\title{
Effects of hydrostatic pressure on surface water microbial communities and microbial POC decomposition in the ocean
}

\author{
YING LIU $^{1}$, LI ZHANG ${ }^{2}$, JIASONG FANG ${ }^{1}$ \\ ${ }^{1}$ SHANGHAI ENGINEERING RESEARCH CENTER OF HADAL \\ SCIENCE AND TECHNOLOGY, SHANGHAI OCEAN \\ UNIVERSITY, SHANGHAI, CHINA \\ ${ }^{2}$ State Key Laboratory of GeOlOGical Process \\ AND MINERAL RESOURCES, SCHOOL OF EARTH \\ SCIENCES, CHINA UNIVERSITY OF GEOSCIENCES, \\ WuHAN, HuBEI, CHINA.
}

Microbially mediated decomposition of particulate organic carbon (POC) constitutes a critical component of the deep ocean carbon cycle and hydrostatic pressure is an important factor affecting this process. Here, we report results of our investigation on the effects of hydrostatic pressure on surface water microbes and microbially mediated POC decomposition. Use of the DNA stableisotope probing technology allowed us to identify particle-attached (PA) and free-living (FL) microbial taxa that actively participated in POC decomposition and DOC utilization. Our results show that only a subset of the original microbial community has participated in the POC decomposition process. Pressure appears affecting microbial succession in lifestyles. However, there is no definitive connectivity between microbial lifestyle (PA vs. FL) and ecological functions. Although PA bacteria had much lower abundance and diversity than FL bacteria, they exhibiited higher POC decomposition activity than FL bacteria. Overall, POC degradation rates showed a graduate decrease with pressure, from $0.0051 \pm 0.0002 \mu \mathrm{mol} C \cdot \mathrm{L}^{-1} \cdot \mathrm{h}^{-1}$ at 0.1 $\mathrm{MPa}$ to $0.0030 \pm 0.0001 \mu \mathrm{mol} \mathrm{C} \cdot \mathrm{L}^{-1} \cdot \mathrm{h}^{-1}$ at 40 $\mathrm{MPa}$. Our results provide important insights into how pressure affects the function and community structure of surface ocean microbes associated with descending particulates in the ocean. 